\title{
Disability and quality of life in patients with different forms of migraine
}

\author{
Domenico D'Amico ${ }^{1 *}$, Matilde Leonardi ${ }^{2}$, Licia Grazzi ${ }^{1}$, Marcella Curone ${ }^{1}$, Alberto Raggi ${ }^{2}$ \\ From Abstracts from the 1st Joint ANIRCEF-SISC Congress \\ Rome, Italy. 29-31 October 2015
}

\section{Background and state of the art}

Migraine (M) is the seventh leading cause of years of life lost to disability (YLDs) worldwide, responsible for $2.9 \%$ of all YLDs, more than half of all YLDs attributable to neurological disorders [1]. Its negative effects result from several studies, particularly in surveys carried out by our research group, through the application of patient oriented outcome measures (PROMS), and in their development and validation [2-4]. Administration of MIDAS (a migrainespecific tool) demonstrated that: the disability level is rather high (particularly in chronic $\mathrm{M}$ ); social, family and leisure activities are more impaired than work activities; days spent at work with reduced effectiveness are more than days of absence [3-5]. A better understanding of the pervasive impact of migraine has been achieved using the WHODAS 2.0, a questionnaire based on the International Classification of Functioning, which captures the interaction between the individual's health status and the context of life. Our data, together with many results deriving from the application of quality of life tools (e.g., SF-36 and MSQ), showed that migraine influences physical and emotional domains, causes restriction and avoidance of activities also outside the headache episodes [6-11].

\section{Measuring the impact of migraine: a relevant issue in different fields}

Migraine has to be considered both as a clinical and as a public health problem: therefore, at least two perspectives need to be taken into account:

1. Epidemiological and healthcare perspectives: to evaluate the burden of migraine in the population, understand patients' needs in implementing appropriate treatments and address healthcare interventions.

\footnotetext{
* Correspondence: damico.d@istituto-besta.it

${ }^{1}$ Headache and Neuroalgology Unit, Neurological Institute C. Besta, IRCCS Foundation, Milan, Italy

Full list of author information is available at the end of the article
}

2. Clinical practice and research perspectives: to assess the severity of migraine in an individual patient, to better tailor treatment plans, and eventually to evaluate their global outcome, and to assess the efficacy of new treatments in RCTs and observational studies.

\section{Concluding remarks and future directions}

Migraine is a common condition, whose impact is relevant on individuals, in terms of personal suffering and reduced health, and on societies, in terms of reduced productivity and increased costs for the health system $[7,8,12]$. The systematic use of PROMs should be encouraged both in the clinical and in the research fields, particularly in RCTs to quantify the potential benefits of treatments. Further (ongoing) research is needed to understand the potential application of the different tools in the different contexts, as well as to develop new instruments to assess the qualitative aspects of migraine-related disability, particularly in the workplace.

Conflict of interest

None declared.

\section{Acknowledgements}

Part of this study was carried out with an unrestricted grant from Allergan.

Authors' details

'Headache and Neuroalgology Unit, Neurological Institute C. Besta, IRCCS

Foundation, Milan, Italy. ${ }^{2}$ Neurology, Public Health and Disability Unit,

Neurological Institute C. Besta, IRCCS Foundation, Milan, Italy.

Published: 28 September 2015

\section{References}

1. Steiner TJ, Stovner $\sqcup$, Birbeck GL: Migraine: the seventh disabler. J Headache Pain 2013, 14:1.

2. D'Amico D, Mosconi P, Genco S, et al: The Migraine Disability Assessment (MIDAS) questionnaire: Translation and reliability of the Italian version. Cephalalgia 2001, 21:947-952.

3. D'Amico D, Grazzi L, Usai S, Leonardi M, Raggi A: Disability and quality of life in headache: where we are now and where we are heading. Neurol Sci 2013, 34:S1-S5. 
4. Raggi A, Giovannetti AM, Schiavolin S, Leonardi M, Bussone G, Grazzi L, Usai S, Curone M, Di Fiore P, D'Amico D: Validating the Migraine-Specific Quality of Life Questionnaire v2.1 (MSQ) in Italian inpatients with chronic migraine with a history of medication overuse. Qual Life Res 2014, 23(4):1273-7.

5. D'Amico D, Grazzi L, Usai S, Rigamonti A, Curone M, Bussone G: Disability pattern in chronic migraine with medication overuse: a comparison with migraine without aura. Headache 2005, 45(5):553-60.

6. Raggi A, Giovannetti AM, Quintas R, D'Amico D, Cieza A, Sabariego C Bickenbach JE, Leonardi M: A systematic review of the psychosocial difficulties relevant to patients with migraine. J Headache Pain 2012, 13:595-606

7. Raggi A, Covelli V, Leonardi M, Grazzi L, Curone M, D'Amico D: Difficulties in work-related activities among migraineurs are scarcely collected: results from a literature review. Neurol Sci 2014, 35:S23-S26.

8. D'Amico D, Grazzi L, Curone M, Di Fiore P, Cecchini Proietti A, Leonardi M, Scaratti C, Raggi A: Difficulties in work activities and the pervasive effect over disability in patients with episodic and chronic migraine. Neurol Sci 2015, 36:S9-S11.

9. Leonardi M, Raggi A, Bussone G, D'Amico D: Health-related quality of life, disability and severity of disease in patients with migraine attending to a specialty headache center. Headache 2010, 50:1576-1586.

10. Raggi A, Leonardi M, Bussone G, D'Amico D: A 3-month analysis of disability, quality of life and disease course in patients with migraine. Headache 2013, 53:297-309.

11. Raggi A, Schiavolin S, Leonardi M, Giovannetti AM, Bussone G, Curone M, Di Fiore P, Grazzi L, Usai S, D'Amico D: Chronic Migraine with Medication Overuse: association between disability and quality of life measures, and impact of disease on patients" lives. J Neurol Sci 2015, 348:60-66.

12. Linde M, Gustavsson A, Stovner LJ, Steiner TJ, Barré J, Katsarava Z, Lainez JM, Lampl C, Lantéri-Minet M, Rastenyte D, Ruiz de la Torre E, Tassorelli C, Andrée C: The cost of headache disorders in Europe: the Eurolight project. Eur I Neurol 2012, 19:703-11.

doi:10.1186/1129-2377-16-S1-A4

Cite this article as: D'Amico et al.: Disability and quality of life in patients with different forms of migraine. The Journal of Headache and Pain 2015 16(Suppl 1):A4.

\section{Submit your manuscript to a SpringerOpen ${ }^{\odot}$ journal and benefit from:}

- Convenient online submission

- Rigorous peer review

- Immediate publication on acceptance

- Open access: articles freely available online

- High visibility within the field

- Retaining the copyright to your article 